\title{
COMMENTAR
}

Research

\section{Implantable cardioverter defibrillators work - so why aren't we using them?}

\section{Christopher S. Simpson MD}

$\infty \quad$ See related article page 4I

$\mathrm{F}$ ew medical therapies pose the issue of how to avoid sudden cardiac death as starkly as does the implantable cardioverter defibrillator - a device that is implanted like a pacemaker, which has been well established as a safe and effective means to reduce the death rate among survivors of cardiac arrest (secondary prevention) ${ }^{1-3}$ and among people at risk for ventricular arrhythmias (primary prevention). ${ }^{4-6}$

The concept is simple. The defibrillator, once implanted, monitors the patient's rhythm and waits. If a ventricular tachyarrhythmia (tachycardia or fibrillation) occurs, the device recognizes it quickly and delivers therapy (overdrive pacing or a shock) to stop the arrhythmia and restore sinus rhythm.

This therapy is easy to explain to patients. It is intuitively compelling. It is safe. And it works: the efficacy of these devices (about $99 \%$ ) is astounding. So - after all these years of experience, after all the studies showing benefit, after all the guidelines recommending implantable cardioverter defibrillators as a class I indication with level A evidence - how is it that we continue to underuse this safe and effective therapy?

Birnie and colleagues ${ }^{7}$ have, in this issue of $C M A J$, provided us with the best estimate to date of the use of this therapy in the secondary-prevention population (i.e., survivors of an out-of-hospital cardiac arrest). The authors make a convincing argument that, although we are making some slow gains, these defibrillators continue to be greatly underutilized, particularly when academic centres are uninvolved in the patient's care. They have found that from 1995 to 2003 , the implantation rate of cardioverter defibrillators into survivors of sudden cardiac death rose in Canada from 5.5\% to $26.7 \%$, whereas in the United States, it has risen from $9.7 \%$ to $42.0 \%$.

Birnie and colleagues have been appropriately cautious in the interpretation of these data: not all sudden deaths are due to ventricular arrhythmias, and they acknowledge that we really don't know what the appropriate rate of defibrillator implantation should be in survivors of sudden cardiac death as a broad group. In their analysis, they carefully excluded a large proportion of patients with reversible causes for their aborted sudden death, since causes such as concurrent myocardial infarction constitute the major legitimate reason to withhold cardioverter defibrillator implantation. It is therefore difficult to explain away the low rate of uptake seen in this study, in a population that appears to be, for the most part, nominally eligible for the therapy.

The persistent difference in defibrillator implant rates in this population between Canada and the United States suggests that there may be important cultural factors that influence related decision-making, which should encourage us to speculate on the potential roles of social, economic, political and geographic factors. Are these between-country differences and the apparent underutilization of implantable cardioverter defibrillators in both countries explained, as the authors suggest, by access deficits, inadequate knowledge translation and guideline underpenetration? Or are these only part of the picture?

\section{Economics and rationing}

The uptake of new technologies into the Canadian health care system is generally slower than in the United States. As monopolies, provincial governments are able to tightly regulate the roll-out of a new technology, by placing caps on the volumes covered by government insurance and by other indirect disincentives for procedures such as defibrillator implantation. Thus, provincial and territorial Ministries of Health are able to force rationing decisions downstream to the physician at the bedside simply by placing limits on how many procedures can be performed every year. ${ }^{8}$ This is less of a concern in the United States, although rationing undoubtedly occurs there as well. During the period of the study (1995-2003), centres in Canada were routinely running out of funding for implantable cardioverter defibrillators well before the end of the fiscal year, which resulted in difficult and inelegant rationing decisions.

\section{Knowledge translation, guideline penetration and access problems}

Physician judgment clearly plays a large role in implant decisions. It is unknown whether physicians are not considering implantable defibrillators at all for potentially eligible pa-

Christopher Simpson is Medical Director of the Cardiac Program, Kingston General Hospital-Hotel Dieu Hospital, and an Associate Professor of Medicine, Queen's University, Kingston, Ont. 
tients, whether they consider but decide against offering it to their patients, whether they offer it but patients decline it, or whether the resources are unavailable or difficult to obtain. Although the greater use of the therapy among patients who came to an academic teaching institute (as opposed to a smaller or community-based institution) strongly supports the existence of inadequate knowledge translation and guideline penetration, it may also reflect a relative unavailability of the resource at smaller community hospitals. One key infrastructural difference between this country and the United States is that defibrillator implantations in Canada are performed almost exclusively in large teaching institutions with full electrophysiology programs, whereas in the United States they are carried out in many medium-sized and small community facilities as well. Certainly, then, Canada's geographic scale and the resulting remoteness of implant facilities for many patients may well factor prominently into decisionmaking. Patients from regions of Canada with no nearby implant centre have previously been shown to have lower implant rates for these devices. ${ }^{9}$

\section{Cultural values, social factors and reduced rates of death}

A decision to implant an implantable cardioverter defibrillator is fundamentally different from a decision to begin drug therapy for, say, hypercholesterolemia. We use drugs for hypercholesterolemia to reduce not only deaths but also illness and disability, and when we introduce a drug to a patient, there is an expectation by both physician and patient that the individual in question will derive benefit.

However, when we implant a cardioverter defibrillator, we know that when it fires, it does only one thing: it prevents sudden cardiac death. It accomplishes nothing else. We also know that most patients implanted with a cardioverter defibrillator will eventually die from something else, never having had their life "saved" by the device. Thus, the implantable cardioverter defibrillator will be truly lifesaving for only a small percentage of those in whom we implant the device, whereas drugs that we prescribe for common conditions like hypercholesterolemia will slightly extend the lives and marginally reduce illness in a greater proportion of treated patients. Patients and physicians thereby perceive these therapies differently. There is no doubt that this weighs into the decision-making process and probably contributes to differences in the general acceptance of drugs versus the general acceptance of implantable cardioverter defibrillators. For example: given the choice, would you prefer to take a statin for 6.I years and extend your life by a statistical average of 34 days, ${ }^{10}$ or have an implantable cardioverter defibrillator that has, say, a one-in-ten chance of truly saving your life sometime over the next 3 years? The risk reductions and $p$ values of these options may be comparable, but the way the benefit is perceived and presented is very different.

Finally, patients who have survived an episode of sudden cardiac death are arguably compelled to consider their own

\section{Key points}

- Birnie and colleagues have demonstrated the marked difference between Canada and the United States with respect to how often implantable cardioverter defibrillators are used in survivors of cardiac death.

- There are considerable administrative and economic barriers in Canada to the adoption of new technologies.

- Other factors that may contribute to the large utilization gap between the 2 countries could include differing cultural and social norms.

- Differences in implant rates between community and academic hospitals suggest a need for increased awareness of the evidence.

- While the reasons for the underuse of this therapy are being researched, physicians should offer it to all patients whose situation meets the guidelines.

mortality in a much more thorough and philosophical way than many other patients do. Many begin thinking about mode of death, and the fact that a reduction in the probability of sudden death (regarded by most as a painless or even "pleasant" way to die) necessarily means that death, when it does come, is more likely to be nonsudden, or less pleasant. Is living longer, only to eventually die in a less palatable way, the preferred course? Clearly, the right answer differs for different people.

Reasons for the relative underuse of implantable cardioverter defibrillators in Canada and the United States for secondary prevention of sudden death are undoubtedly multifactorial. More investigation is required to examine the reasons for the difference between Canada and the United States. In the interim, efforts should be made to ensure that all physicians are aware of this option for survivors of sudden cardiac death. Paternalism and bedside rationing should be discouraged; physicians should instead engage their patients in a discussion about the benefits versus the potential downsides of implantable cardioverter defibrillator therapy and advocate for their patients to secure this treatment when appropriate. Patients who are eligible according to guidelines deserve to be offered the therapy; but they also must be empowered to refuse it if, after being fully informed, they determine that it is not the right choice for them.

This article has been peer reviewed.

Competing interests: Dr. Simpson has received honoraria and speaker's fees from Medtronic and Boston Scientific.

\section{REFERENCES}

I. The Antiarrhythmics versus Implantable Defibrillators AVID Investigators. A comparison of antiarrhythmic drug therapy with implantable defibrillators in patients resuscitated from near-fatal ventricular arrhythmias. N Engl J Med I997; 337:1576-83.

2. Connolly SJ, Gent M, Roberts RS, et al. Canadian Implantable Defibrillator Study (CIDS): a randomized trial of the implantable cardioverter defibrillator against amiodarone. Circulation 2000;10I:1297-302.

3. Kuck KH, Cappato R, Siebels J, et al. Randomized comparison of antiarrhythmic drug therapy with implantable defibrillators in patients resuscitated from cardiac arrest: the Cardiac Arrest Study Hamburg (CASH). Circulation 2000;102:748-54. 
4. Bardy GH, Lee KL, Mark DB, et al. Amiodarone or an implantable cardioverterdefibrillator for congestive heart failure [published erratum in N Engl J Med 2005; 352:2146]. NEngl J Med 2005;352:225-37

5. Kadish A, Dyer A, Daubert JP, et al. Defibrillators in non-ischemic cardiomyopathy treatment evaluation (DEFINITE). N Engl J Med 2004;350:2I5I-8.

6. Moss AJ, Zareba W. Hall WJ at al. Multicenter Automatic Defibrillator Trial II Investigators. Prophylactic implantation of a defibrillator in patients with myocardial infarction and reduced ejection fraction. N Engl J Med 2002;346:877-83.

7. Birnie DH, Sambell C, Johansen H, et al. Use of implantable cardioverter defibrillators in Canadian and US survivors of out-of-hospital cardiac arrest. CMAJ 2007; I77:4I-6.

8. Simpson CS, Hoffmaster B, Dorian P. Downward delegation of implantable cardioverter defibrillator decision-making in a restricted-resource environment: the pitfalls of bedside rationing [review]. Can J Cardiol 2005;21:595-9.
9. Wilson S, Kadwell S, Kane C, et al. Variations in utilization of implantable cardioverter defibrillators across Canada. Can J Cardiol 2004;20(Suppl D):I47D.

Io. The Long-Term Intervention with Pravastatin in Ischaemic Disease (LIPID) Study Group. Prevention of cardiovascular events and death with pravastatin in patients with coronary heart disease and a broad range of initial cholesterol levels. $\mathrm{N} \mathrm{EnglJ}$ Med I998;339:1349-57.

Correspondence to: Dr. Christopher Simpson, Department of Cardiology, FAPC Level 3, Kingston General Hospital, 76 Stuart St., Kingston ON K7L 2V7; fax 613 548-1387; simpsonc@kgh.kari.net

\title{
Canada's health care system and the sustainability paradox
}

\author{
Irfan Dhalla MD
}

$\infty$

See related article page 54

$\mathrm{P}$ hysician leaders, ${ }^{1}$ newspaper columnists, ${ }^{2,3}$ representatives of the business community ${ }^{4}$ and even some health policy analysts ${ }^{5}$ have all expressed concerns that publicly funded health care is unsustainable. The current federal health minister has even gone so far as to say that "both the Prime Minister and I have indicated that the status quo won't be sustainable in terms of demands on our system."

Not everyone holds this view. For example, in his report on health care in Canada, ${ }^{7}$ Roy Romanow concluded that our health care system was "as sustainable as we want it to be." Despite this countervailing argument, concerns about unsustainability have provided an impetus for proposed reform. ${ }^{1}$

In this article, I will argue that Canada faces a sustainability paradox: despite ever-increasing expenditures, both in absolute dollars and as a percentage of the national income, increases in overall spending on health care in Canada are sustainable for the foreseeable future.

\section{Are increases in government spending on health care sustainable?}

One view maintains that our publicly funded health care system is unsustainable because health care expenditures are accounting for an ever-increasing share of government spending. In Ontario, for example, health care spending accounted for just over $30 \%$ of the provincial government's expenditures in $198 \mathrm{r} / 82$, but $45 \%$ in $2004 / 05$. Assuming that current trends will continue, the Ontario government has projected that the share will increase to $55 \%$ by $2025 .{ }^{8}$

One major flaw with this line of reasoning is the assump- tion that the percentage of government expenses devoted to health care depends primarily on how much governments spend on health. When measured by percentage of government expenses, health spending also depends on 2 other key factors: how much governments spend on non-health-related items (e.g., education, police services, social assistance) and how much governments collect in taxes. If a government reduces its spending on non-health-related items or cuts taxes, the percentage of expenditures devoted to health care will increase automatically.

A closer look at the Ontario data described earlier reveals that other trends are hidden amid the seemingly inexorable rise in health care spending. For example, starting in 1988 , the share of Ontario's expenditures devoted to health care actually decreased for almost io years, from $38 \%$ to just over $35 \%$. After 1997, the share began to grow, but the increase was due in large part to reductions in spending on nonhealth-related items, tax cuts and reductions in transfers from the federal government. ${ }^{8}$

Arguments that our publicly funded health care system is unsustainable because it accounts for an ever-increasing share of government funding often depend on the premise that tax rates must be fixed or continually declining. This as-

Irfan Dhalla is with the Departments of Medicine at St. Michael's Hospital and at the University of Toronto, and with Canadian Doctors for Medicare, Toronto, Ont.

Une version française de cet article est disponible à l'adresse www.cmaj.ca/cgi/content/full/I77/I/5I/DCI 